\title{
Pautas de consumo de noticias en las nuevas generaciones. Un análisis aplicado a estudiantes de periodismo de la Universidad de Sevilla
}

\section{Media consumption patterns on new generations. Behavioral analysis applied to journalism students from the University of Seville}

\author{
Dra. Luisa Graciela Aramburú Moncada \\ Universidad de Sevilla \\ laramburu@us.es \\ ORCID: https://orcid.org/0000-0002-0409-5380 \\ Dr. Isaac López Redondo \\ Universidad de Sevilla \\ ilopez6@us.es \\ ORCID: https://orcid.org/0000-0001-9426-6683
}

Resumen: La evolución de la tecnología está acelerando el cambio del ecosistema de medios de comunicación y generando innovadores modelos informativos que cada vez logran conectar más a las nuevas generaciones. Jóvenes fascinados por la accesibilidad, la conectividad y la inmediatez que internet ofrece. Son esos nuevos escenarios mediáticos los que constituirán el entorno natural del periodismo de mañana. Las futuras generaciones de periodistas han nacido de la mano de dispositivos como smartphones, tablets u ordenadores portátiles, que constituyen herramientas laborales tan naturales hoy día como lo han sido un bolígrafo y una libreta para generaciones anteriores. Esta realidad, cada vez más latente, exige al periodismo adaptarse a esa innovadora cultura de red y asumir las transformaciones necesarias que garanticen su rol primordial de "perro guardián de la sociedad”. Por otra parte, ¿qué tipo de prensa consumen los futuros periodistas? ¿Con qué frecuencia? ¿A través de qué canales? El presente trabajo constituye un estudio sobre los hábitos de consumo de información de los estudiantes universitarios de hoy, periodistas del mañana, descubriendo y analizando sus gustos, intereses y afinidades. Este estudio pretende aportar luz sobre la evolución del periodismo, su conexión con las nuevas tecnologías, las fuentes de acceso a la información por parte de los jóvenes y el papel de los periodistas del mañana. Para ello se llevarán a cabo una serie de encuestas a estudiantes de periodismo de la Universidad de Sevilla para su posterior análisis cuantitativo y cualitativo de los resultados obtenidos. 
Abstract: The evolution of the technology is accelerating the change of the media ecosystem and generating innovative information models that increasingly connect to new generations. Young people fascinated by the accessibility, connectivity and immediacy that the internet offers. These are new media scenarios that will constitute the natural environment of tomorrow's journalism. The future generations of journalists have been born handling devices such as smartphones, tablets or laptops, which are today as natural work tools as have been a pen and a notebook for previous generations. This reality, more and more latent, requires journalism to adapt to this innovative network culture and assume the necessary transformations that guarantee its primordial role as the "guardian dog of society". On the other hand, what type of press do the future journalists consume? How often? Through what channels? The present work constitutes a study on the habits of information consumption of the university students of today, journalists of tomorrow, discovering and analyzing their likes, interests and affinities. This study aims to shed light on the evolution of journalism, its connection with new technologies, sources of access to information by young people and the role of tomorrow's journalists. To this end, a series of surveys will be carried out to journalism students of the University of Seville for their subsequent quantitative and qualitative analysis of the results obtained.

Palabras clave: Consumo informativo, juventud, periodismo, internet.

Keywords: Informative consumption, youth, journalism, internet.

\section{INTRODUCCIÓN}

Desde que el canadiense McLuhan (1989) desarrollara la idea de aldea global para explicar el desarrollo de los medios de comunicación masiva y su influencia en la desaparición de las distancias físicas engendrando conocimiento, el mundo de la información no ha dejado de estar en perpetuo cambio y movimiento. La irrupción de las nuevas tecnologías exige a sus profesionales un reto constante de innovación y renovación para competir y mantenerse dentro del nuevo escenario mediático. Uno que probablemente McLuhan no había imaginado. En estos nuevos tiempos, internet democratiza el acceso a las noticias y fuerza constantemente la transformación del ecosistema de medios de comunicación generando innovadores modelos informativos que buscan ofrecer también nuevas formas de interacción y participación entre sus periodistas con sus lectores, audiencias o usuarios.
Estas modernas plantillas informativas logran cautivar y conectar más con las generaciones de jóvenes, fascinados por la accesibilidad, la conectividad y la inmediatez que internet ofrece, hasta tal punto, que hoy incluso podemos sostener que las redes sociales han democratizado a los medios de comunicación. Redes sociales utilizadas mayoritariamente por los jóvenes. Investigaciones como la de Kim et al. (2013) confirman la relevancia que los estudiantes universitarios ofrecen en su búsqueda de información a las redes sociales. En ello, sostiene el investigador, influye tanto la disciplina estudiada como el género. Condeza, Bachmann y Mujica (2014) detectan tres motivaciones fundamentales que van desde el monitoreo de la actualidad, el entretenimiento hasta lo que denomina utilidad social de estar constantemente en contacto con la actualidad. 
Qué duda cabe, la era digital está cambiando la forma de recibir las noticias. Sin embargo, haciendo una mirada retrospectiva en el tiempo veremos que el periodismo siempre ha incorporado las innovaciones tecnológicas a la profesión de una forma natural. Martín Algarra (2005: 10), destaca el vínculo directo que existe entre el desarrollo tecnológico y la evolución del periodismo:

La tecnología no es una circunstancia en la comunicación periodística. Es un elemento nuclear en su existencia y cualquier reflexión sobre ella debe contar con que el Periodismo, sea del tipo que sea, como la comunicación, sea del tipo que sea, exige de un proceso de producción más o menos sofisticado que permita hacer visible la realidad que se quiere compartir.

Una realidad que cada vez se comparte con una mayor rapidez. En las últimas décadas, la tecnología ha avanzado a pasos tan agigantados que está creando un entorno muy conectado a la red. Las transformaciones que se producen influyen en la exigencia de la renovación de la industria de las telecomunicaciones y demandan la utilización de los entornos digitales encauzados a atraer y conquistar a un público cada vez más amplio y heterogéneo. Más aún en la era de la información en la que las personas pueden rápidamente hasta generar noticias. El investigador Varela (2005: 12) sostiene al respecto:

Los ciudadanos se han apropiado de la información a través de los medios sociales. La crisis de la credibilidad de la prensa tradicional, el cuestionamiento de la objetividad y la aparición de herramientas digitales accesibles a todos, convierten el periodismo en una conversación de la que los ciudadanos más activos no quieren estar ausentes.

Entre esos ciudadanos más activos destacan los millennials y generación $z$ fascinados en la búsqueda y consumo de los diversos productos y entornos que ofrece internet. Los nativos digitales son para Marc Prensky (2008) aquellos "hablantes naturales" de lenguajes analógicos con los ordenadores, las consolas de videojuegos o internet, caracterizados por haber nacido y crecido rodeados de tecnología teniendo como parte integral de su existencia los smartphones, tablets $u$ ordenadores portátiles $y$ habituados a comunicarse con emails y chats. En ese mismo sentido Livingstone (2011) agrega que son pioneros en el uso de la red frente a sus experimentados padres, los inmigrantes digitales, a los que superan en calidad y cantidad. En la conectividad no solo encuentran un medio de entretenimiento sino también un medio de circulación de la información. Ellos empiezan a alterar las pautas de consumo periodístico presente en generaciones anteriores, como baby boomers o generación $x$, más analógicas $y$ con menos necesidad de conectividad.

Ante estos hechos, no sorprende que estos jóvenes habituados a la inmediatez de internet formen parte de ese grueso de la población que deja de leer los diarios impresos o que inclusive están declinando acercarse a los periódicos digitales para encontrar en las redes sociales (Yuste, 2015) la fórmula de estar informados. Según el estudio " $20^{\circ}$ Navegantes en la Red-Encuenta a usuarios de Internet 2018", llevado a cabo en España por la Asociación para la Investigación de Medios de Comunicación, crece la hegemonía de las redes sociales Facebook $(85,6 \%)$, Istagram $(47,1 \%)$ y twitter $(46,4 \%)$, utilizándolos para relaciones de amistad $(72,6 \%)$ y para estar informados de la actualidad $(56,0 \%)$. Mientras que los internautas que las utilizan para el seguimiento a un medio de comunicación llegan a un $58,4 \%$, un $35,3 \%$ las usan para seguir a un periodista. Esta preferencia también 
se ve claramente reflejada en el mayor uso de las aplicaciones/APPS para las redes sociales, un $73,6 \%$, que para las aplicaciones de información, un $41,7 \%$. Como refleja el estudio, las redes sociales están logrando tener cada vez más conectados a ususarios/ lectores con sus modelos de información similares a los periódicos digitales y se han convertido con sus accesos gratuitos en serios competidores para las empresas periodísticas afectadas por los costes económicos derivados de su propia actividad.

Los periódicos transitan por arenas movedizas y muy peligrosas. Aunque a lo largo de su historia han paliado el aumento y disminución del número de sus lectores, ahora reinventarse constituye una necesidad de vital importancia. Más aún dentro de la era digital que marca una revolución tecnológica que está transformando profundamente los hábitos, el lenguaje, la vida y las costumbres de millones de personas. El escenario parece señalar la urgencia de un giro regresivo que ofrezca un salto de lo global a lo local ya que la información dentro de las preferencias de los ciudadanos encamina otros linderos. Así lo afirma Mike Jenner, citado por Reese (2014): "Periódicos de propiedad local tienden a ser más sensibles con los lectores y les permiten mantenerse en contacto con su propiedad".

Frente a este mundo tan cambiante para el periodismo en el que la velocidad de la información se ha multiplicado y donde el ciudadano está constantemente bombardeado por noticias, se hace necesario conocer las preferencias informativas de los jóvenes que serán los periodistas del mañana. El nuevo ecosistema de medios de comunicación así lo exige. Los innovadores modelos informativos deben generarse desde el conocimiento de aquellos que la liderarán. En estas nuevas generaciones de jóvenes, el oficio de informar debe tener su punta de lanza. Han nacido y se desarrollan con naturalidad dentro del escenario mediático y dentro de la cultura de red que los hace identificarse desde adentro con el nuevo escenario del periodismo del futuro. La información busca otra manera de atraer lectores y a ellos se les debe ofrecer los conocimientos y herramientas necesarias para desarrollarlas con solvencia. De aquí la importancia de la Universidad a la hora de formar periodistas que cuenten además de las destrezas necesarias, con la capacidad de reflexión que requiere esta profesión indispensable para tener bien informados a la sociedad y para defender la democracia.

En este sentido, debemos tomar en cuenta que los universitarios del siglo XXI han experimentado una transformación radical. Sus diferencias con otras generaciones superan cualquier tipo de analogía. Su cambio es muchos más profundo, complejo y trascendental. Con una "singularidad" muy importante que ofrece "una discontinuidad motivada" producida por el veloz desarrollo de la tecnología digital. Prensky (2008: 5) entiende de esta manera la necesidad de conectar en las aulas con estas generaciones:

Resulta evidente que nuestros estudiantes piensan y procesan la información de modo significativamente distinto a sus predecesores. Además, no es un hábito coyuntural sino que está llamado a prolongarse en el tiempo, que no se interrumpe sino que se acrecienta, de modo que su destreza en el manejo y utilización de la tecnología es superior a la de sus profesores y educadores.

En este nuevo escenario, la enseñanza del periodismo debe adecuarse a estas transformaciones y como sostiene Prensky son "los profesores, inmigrantes digitales" quienes deben especializarse en "guiar a los 
estudiantes, proporcionándoles preguntas y contextos" que garanticen un aprendizaje de calidad. Hoy más que nunca, necesitamos conocer el comportamiento como consumidores de noticias de aquellos jóvenes que serán, además, protagonistas del periodismo del futuro.

\section{OBETIVO GENERAL Y ESPECÍFICOS}

En este artículo analizamos los hábitos de consumo de informaciones de los estudiantes de periodismo de la Universidad de Sevilla para conocer su conducta y predisposición con respecto a noticias, medios de comunicación e internet. Planteamos los siguientes objetivos secundarios:

- Observar si los medios digitales están influyendo, de alguna manera, en el consumo de noticias.

- Determinar si la posible existencia de un cambio de patrón en los hábitos informativos cambian la concepción de confiablidad depositada en los medios tradicionales.

- Concluir si se observan diferencias significativas en los hábitos de consumo de noticias entre estudiantes de distintos cursos.

Con esta investigación ofreceremos una de las primeras radiografías de los hábitos de consumo de noticias entre los estudiantes de periodismo realizados en España.

\section{METODOLOGÍA}

Para la consecución de los objetivos planteados se han analizado los hábitos de consumo de los estudiantes de periodismo teniendo como base una encuesta de carácter exploratorio, siguiendo el modelo planteado por Humanes y Roses (2014), usado un criterio de conveniencia basado en nuestra red de la consulta y percepción colaboración académica para la elección de la universidad pública donde se ha realizado la exploración. Se han seleccionado a estudiantes de primer a cuarto curso de periodismo para comprobar si las percepciones sobre los aspectos mencionados varían a lo largo de los años, según avanzan sus estudios de Periodismo.

En total se han obtenido 176 encuestas cumplimentadas, realizándose las mismas en los primeros meses del año 2018. La encuesta ha sido remitida online y elaborada a través de uno de los fórmularios disponibles en la plataforma de Google, seleccionando la opción disponible "Limitar a 1 respuesta" para evitar el número de duplicidades en las encuestas, es decir, más de un envío por parte de un mismo encuestado. El cuestionario constaba de 10 preguntas, 6 de ellas con respuesta múltiple, estimándose un requerimiento temporal para su cumplimentación de menos de 5 minutos. En la elaboración de la encuesta se han tenido en cuenta los diferentes aspectos que tienen que ver con de la actualidad por los jóvenes, las preferencias por los medios de comunicación online o tradicionales, los dispositivos utilizados para la consulta de noticias, la credibilidad de medios de comunicación tanto "analógicos como digitales", la periodicidad en el acceso a las noticias o los grupos de afinidad con los que comparten los encuestados noticias de interés. Así como una ordenación de noticias atendiendo al interés temático que despiertan. En varias de las preguntas se ha utilizado la escala de Likert para determinar el valor que le confieren a cada uno de los ítems sugeridos. Los datos obtenidos han servido para la elaboración de los gráficos que se presentan y 
los valores de las respuestas. Se incluyen en el Anexo I.

\section{RESULTADOS}

Para el trabajo de investigación se ha seleccionado una muestra aleatoria representativa por curso (de primero a cuarto) para los estudiantes de Periodismo de la Universidad de Sevilla. La muestra utilizada está compuesta por encuestas de 176 individuos.

\subsection{Estratificación de la muestra}

La muestra ha sido estratificada por curso, esto permite evitar desequilibrios causados por concentración de respuestas de estudiantes de unos años respecto a otros, aumentando así la robustez de los resultados. Al mismo tiempo esta distribución permitirá, a nivel de microdatos, no sólo obtener unos resultados sobre el colectivo, sino además, una desagregación por año de estudios que permitirá una mayor profundidad y alcance en el análisis de la encuesta.

Así, los porcentajes de universitarios encuestados oscilan entre el $17,61 \%$ de los alumnos de primer curso y el $29,55 \%$ correspondientes a estudiantes de tercer curso.

Gráfico 1: Estratificación de la muestra de la encuesta.

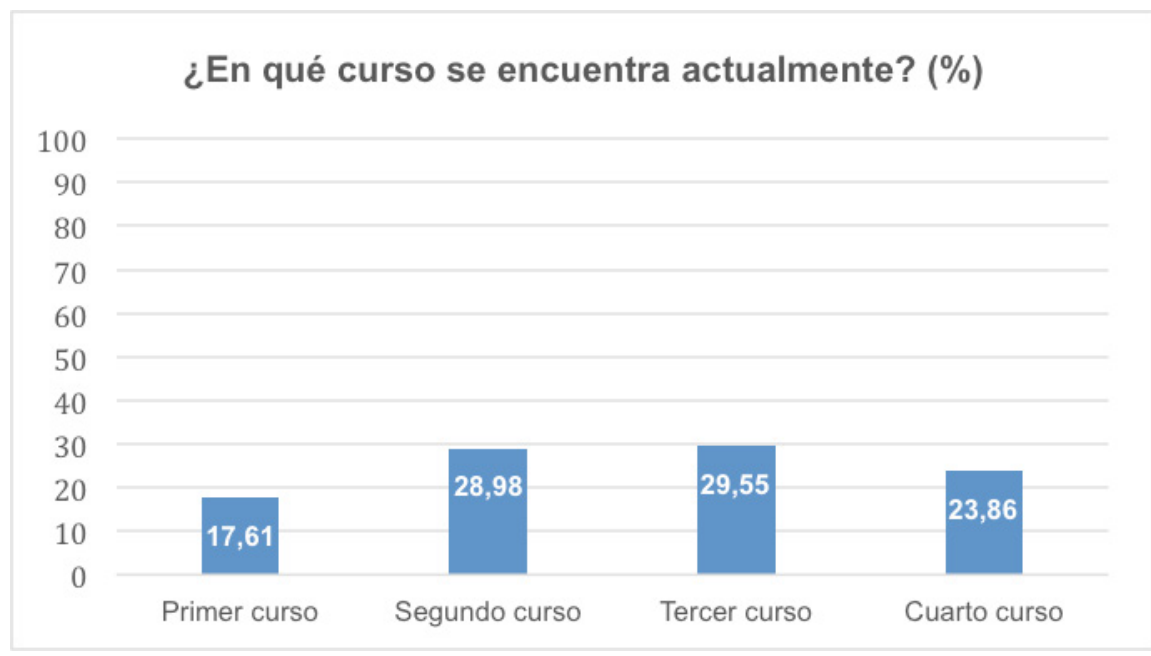

Fuente: elaboración propia

\subsection{Análisis de datos}

Es interesante destacar que los estudiantes de periodismo, en cuanto a preferencias informativas, a nivel agregado, prefieren la prensa digital o internet para informarse $(40,91 \%)$, seguida de las redes sociales $(26,14 \%)$. Medios otrora masivos en el consumo de información como televisión o radio solo son preferidos en un $10 \%$ de los casos, siendo la prensa escrita el medio menos elegido como preferido por los estudiantes para propósitos informativos (6,25\%). Queda evidenciado un cambio de patrón en los hábitos de consumo de información en las nuevas generaciones trasvasándose desde medios "analógicos" hacia medios "digitales". 
Gráfico 2: Preferencias por medio de comunicación / plataforma a nivel agregado.

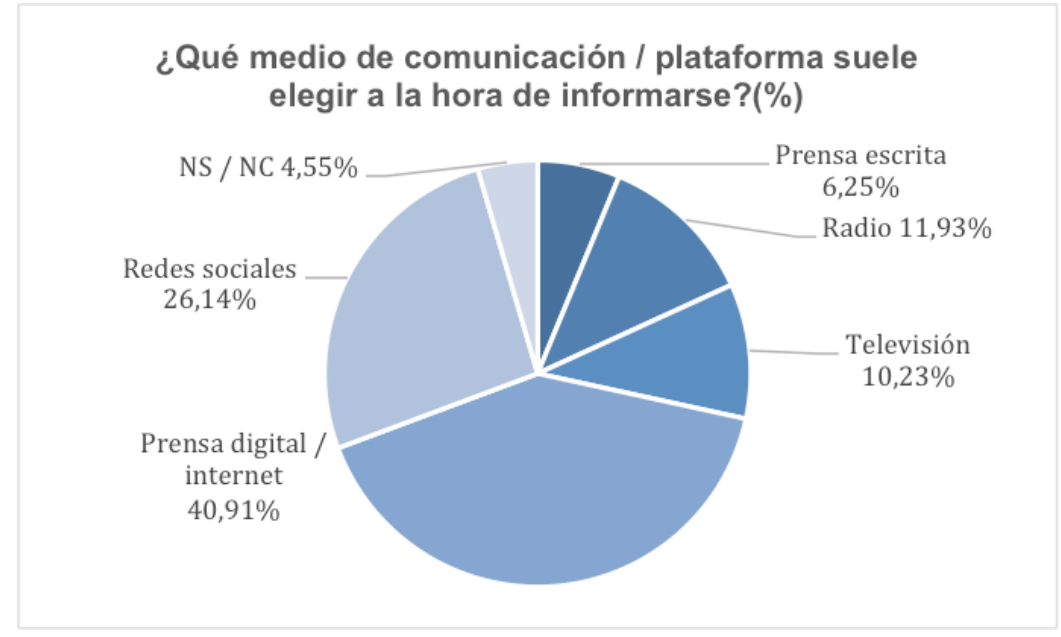

Fuente: elaboración propia.

Con respecto a la información desagregada por año de frente a la radio, en los últimos cursos la radio se estudios (gráfico 3), existe bastante homogeneidad en prefiere a la televisión. Por tanto, a medida que se las preferencias a la hora de elegir un medio. En torno avanza en el nivel de estudios, se consume más radio al $40 \%$ de los estudiantes de todos los cursos optan y menos televisión a efectos informativos. por la prensa digital como primer medio, seguido por También existe homogeneidad en los resultados en las redes sociales que es elegida en segundo lugar cuanto a la prensa tradicional escrita, que se revela como canal preferido por más del $20 \%$ sobre el total de alumnos de cada año. Es importante destacar la evolución de los canales de radio y televisión, éstos, como preferida en porcentajes muy bajos, siendo incluso marginal para los estudiantes de cuarto curso aunque en porcentajes muy bajos de preferencia siguen una evolución dispar. Si bien en los primeros $\quad(40,48 \%)$.

años de estudio la televisión se revela como preferida (2,38\% del total de estudiantes de su grupo), que se decantan en su mayoría por la prensa digital o internet

Gráfico 3: Preferencias por medio de comunicación / plataforma desagregado por curso.

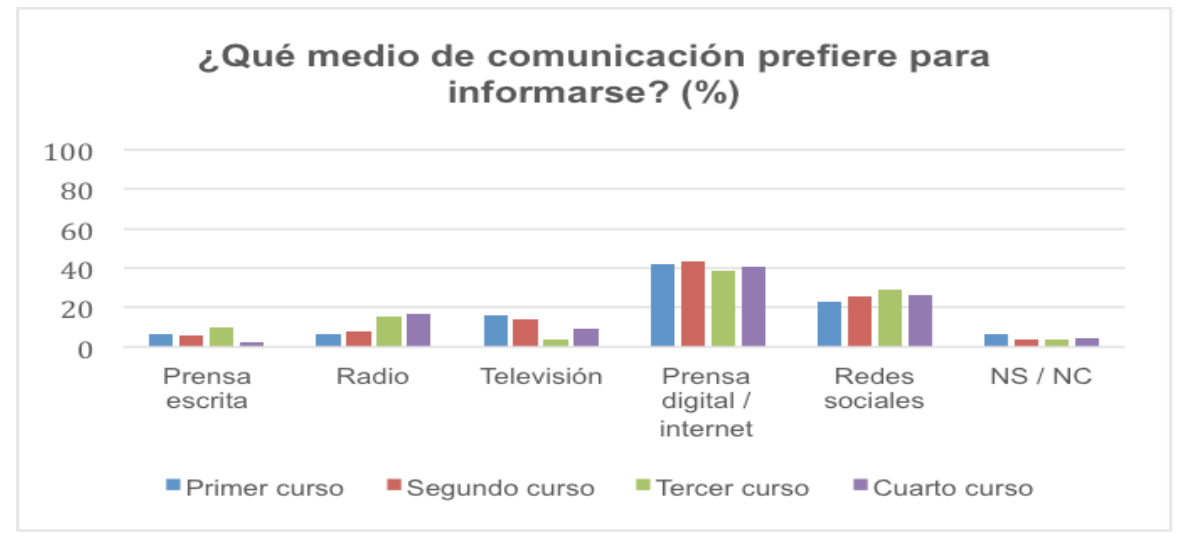

Fuente: elaboración propia. 
En cuanto al consumo de "noticias digitales" que internet se utilizan en primer lugar en más de un $35 \%$ se puede observar en el gráfico 4, las herramientas de los casos, seguido por las redes sociales con un más utilizadas son las de mayor accesibilidad dentro $34 \%$. de cada entorno. Así, los navegadores estándar de

Gráfico 4: Modo de acceso a las "noticias digitales" a nivel agregado.

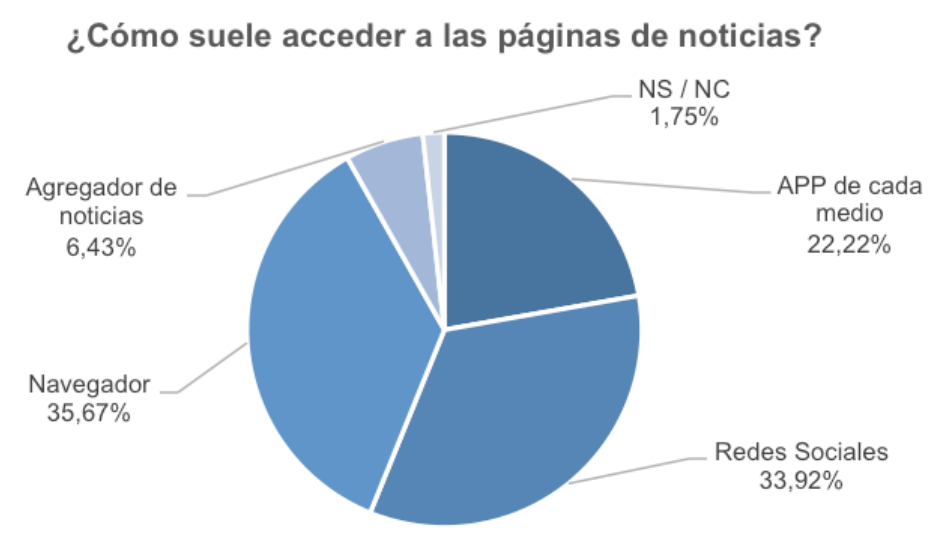

Fuente: elaboración propia.

También cuentan con aceptación las APP específicas Analizando por curso (gráfico 5), el empleo del de cada medio, que se utilizan en un $22 \%$ de los encuestados como forma de acceso principal a las noticias. Sin embargo, el uso de los agregadores de noticias es ciertamente residual entre la comunidad universitaria examinada con tan sólo un $6 \%$. navegador decrece en los últimos años frente al mayor uso de las redes sociales que se sitúan en un $40 \%$ como modo de acceso preferido en tercer y cuarto curso. Sin embargo, el navegador, como forma de acceso universal, es el modo de acceso favorito en los primeros años de estudios.

Gráfico 5: Modo de acceso a "noticias digitales" desagregado por curso.

¿Cómo suele acceder a las páginas de noticias?

(\%)

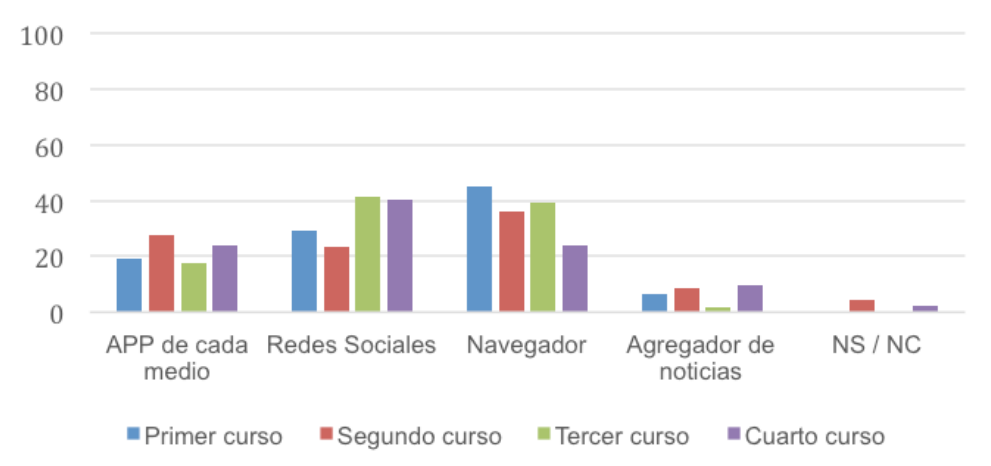

Fuente: elaboración propia. 
La permanente conexión a las redes sociales y Con respecto al dispositivo utilizado a nivel agregado el intercambio de noticias y enlaces a través de (gráfico 6), existe un uso masivo de los teléfonos redes sociales influyen en los estudiantes de los inteligentes para el acceso a la información (72\% últimos años que ya comienzan a convertirse en de los encuestados), seguido por los ordenadores consumidores de noticias de una forma más intensa. portátiles (23\%), siendo marginal la tablet como Acuden a las redes sociales conociendo el poder modo de acceso (4\%). Sin duda, la universalización de comunicación y actualización que tienen estos y popularidad de los smartphones en la sociedad medios que transforman en informadores a todos los de hoy, y su intensivo uso por parte de los jóvenes participantes en la red, desplazando así el uso del los convierten en un canal de acceso masivo a la navegador como herramienta de acceso a contenidos información. periodísticos digitales.

Gráfico 6: Dispositivo utilizado para el consumo de prensa digital a nivel agregado

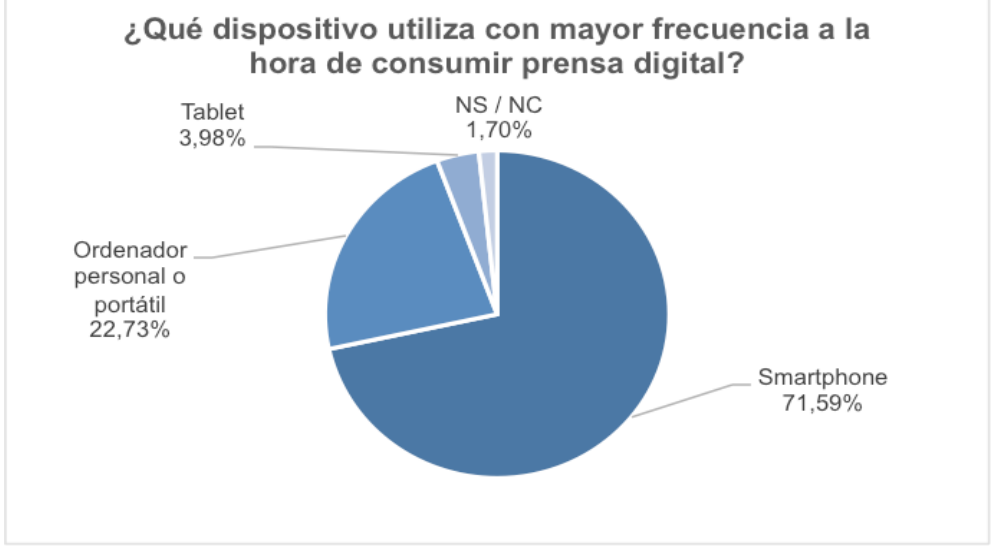

Fuente: elaboración propia.

En cuanto a la desagregación por año de estudios superiores, llegando hasta a un $76 \%$ en el último año (gráfico 7), se observa en el gráfico 7 un aumento frente al $68 \%$ de uso en primero. del consumo de noticias vía smartphone en los curso

Gráfico 7: Dispositivo utilizado para el consumo de prensa digital desagregado por curso.

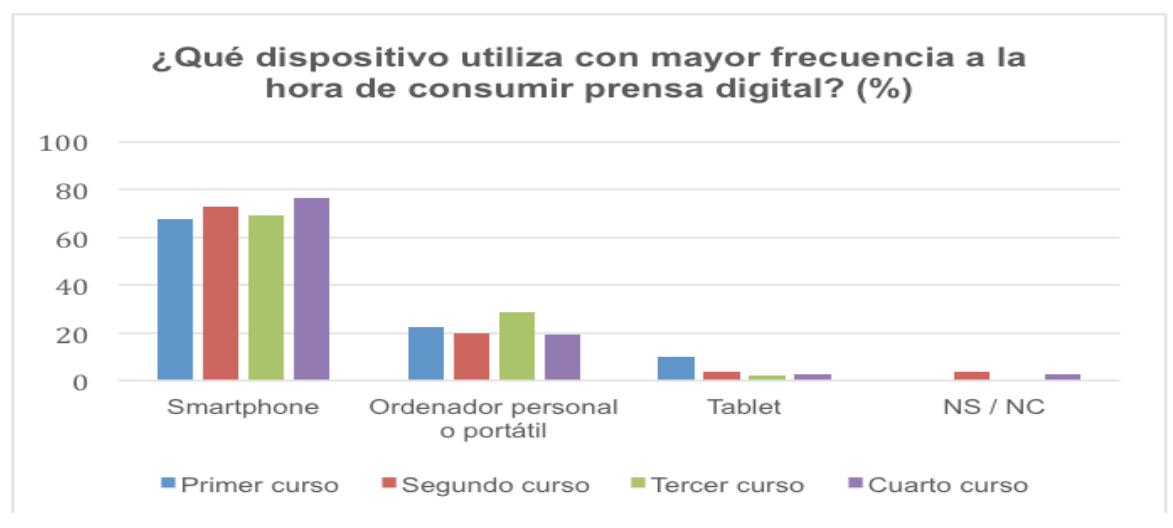

Fuente: elaboración propia. 
La accesibilidad y movilidad que proporcionan estos dispositivos contribuyen a intensificar su uso para acceder a la actualidad informativa a medida que aumentan las inquietudes por las noticias en cursos superiores frente a los primeros años.

La frecuencia de acceso al consumo de información (gráfico 8) es mayoritariamente diaria. Este aspecto está relacionado con facilidad y movilidad que permiten los dispositivos preferidos para estar informado (smartphones), junto con la sensibilidad específica que tiene el colectivo analizado (estudiantes de periodismo) en cuanto a la cercanía a las novedades informativas.

Gráfico 8: Frecuencia de acceso a la información a nivel agregado.

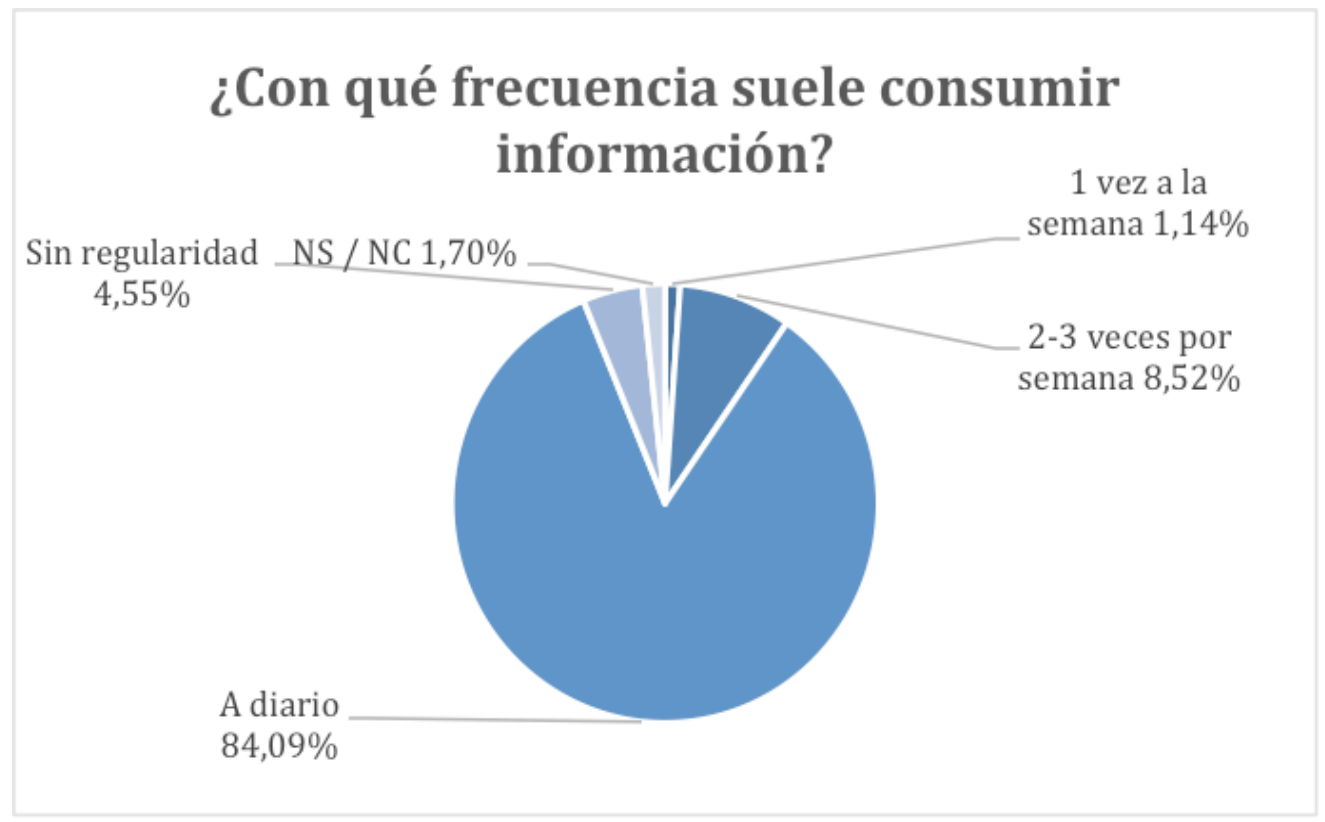

Fuente: elaboración propia.

Aunque no existen diferencias significativas en la frecuencia de consumo de información, se puede advertir que los estudiantes de periodismo de cursos superiores consumen noticias a diario hasta en un $90 \%$ de los casos. Esto demuestra una mayor inquietud informativa que junto con la facilidad de acceso a las noticias contribuyen a este elevado porcentaje.

Enelgráfico10seobservaqueelcolectivodeestudiantes de periodismo prefiere consumirinformación gratuita en un $60 \%$ de las ocasiones, no obstante, estaría dispuesto a pagar por ella para obtenerla en un $31 \%$ de los casos. Lo que constituye un interesante indicador de que se trata de un producto (las noticias) al que le conceden un valor intrínseco y que actualmente lo consumen gratuitamente porque así se ofrece, pero que estarían predispuestos a pagar una cantidad moderada por obtenerla. 
Gráfico 9: Modo de acceso a "noticias digitales" desagregado por curso.

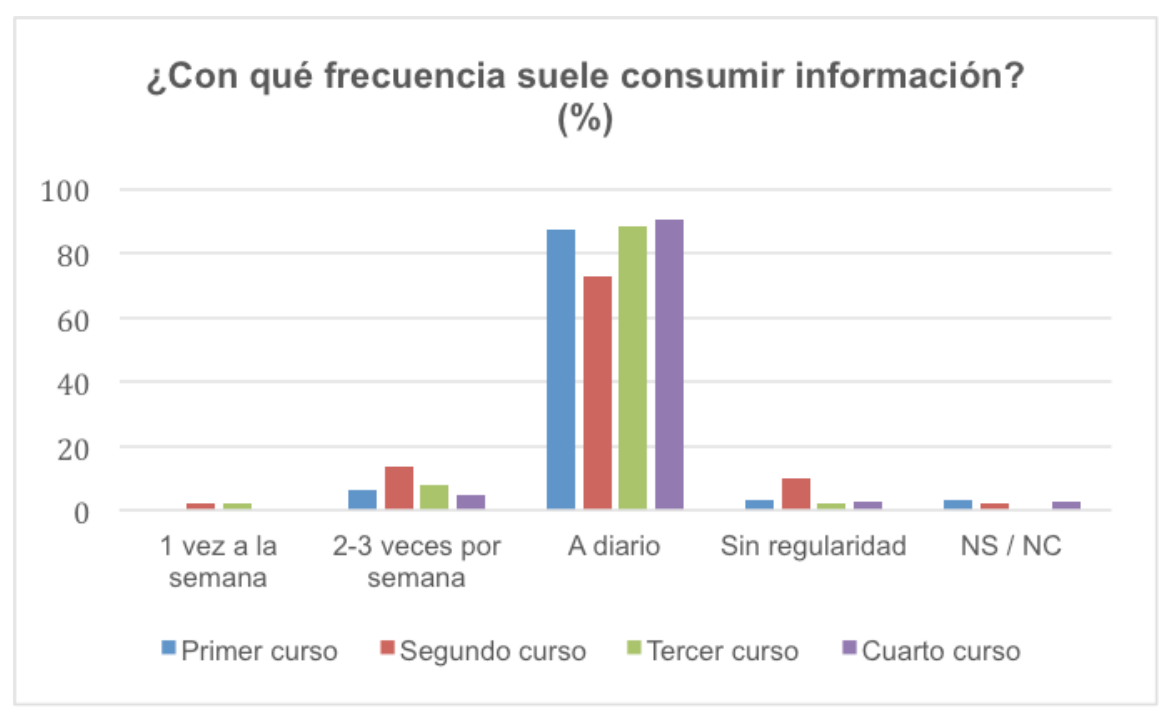

Fuente: elaboración propia.

Esta circunstancia representa una evolución con al pago por consumo de noticias digitales es patente, respecto a las preferencias por la gratuidad apuntadas frente a la disponibilidad observada a pagar por por Casero-Ripollés (2012), en las que las reticencias noticias "impresas".

Gráfico 10: Suscripción a diarios digitales a nivel agregado.

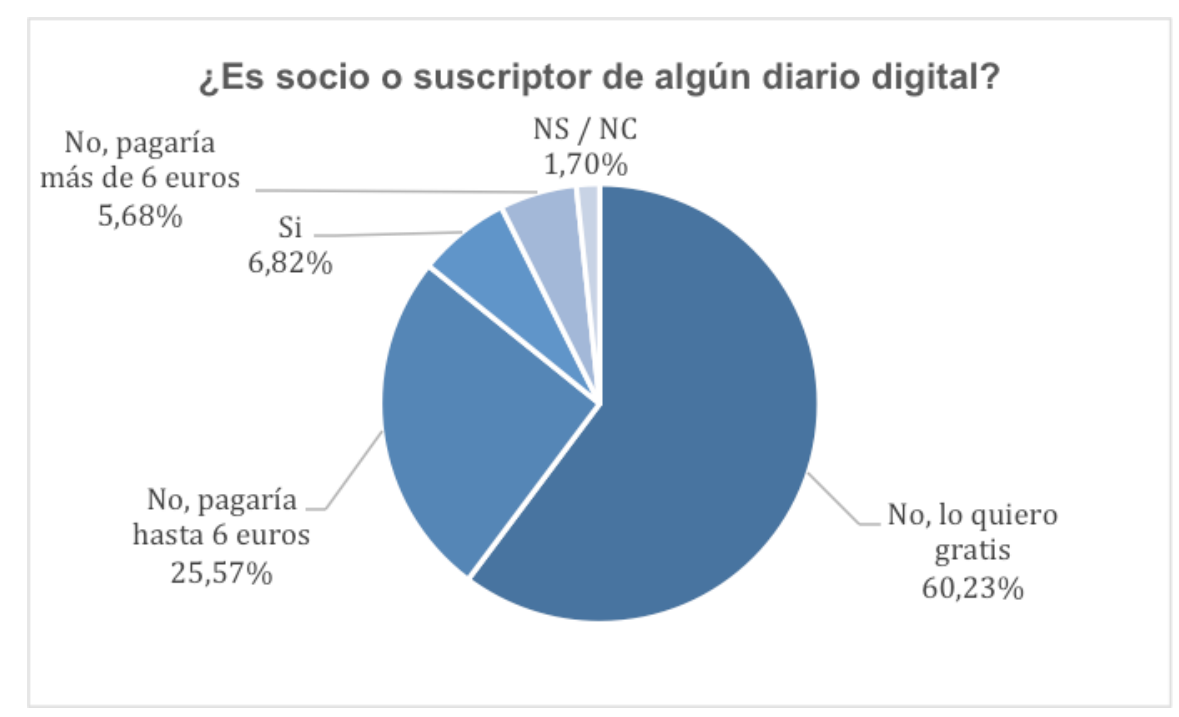

Fuente: elaboración propia.

Las preferencias por la gratuidad son más acusadas valor al consumo de noticias, por ello están dispuestos en el primer año de estudios universitarios (gráfico a ofrecer un precio para su obtención.

11). Mientras que en cursos superiores le otorgan más 
Gráfico 11: Suscripción a diarios digitales desagregado por curso.

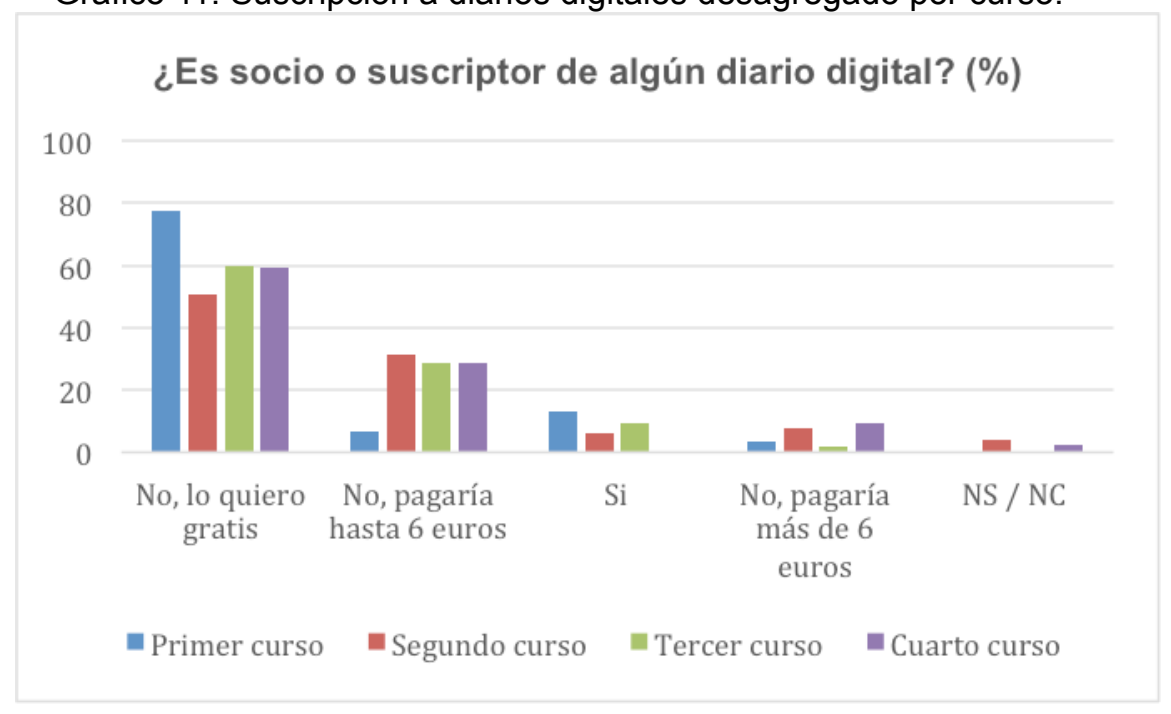

Fuente: elaboración propia.

A nivel agregado (gráfico 12), es la prensa escrita la el más veraz, seguido de la radio (20\%) y de la prensa que goza de un mayor grado de credibilidad, el $46 \%$ digital (13\%). de los estudiantes entrevistados lo consideran como

Gráfico 12: Credibilidad de los medios a nivel agregado.

\section{¿Qué medio considera que tiene más credibilidad?}

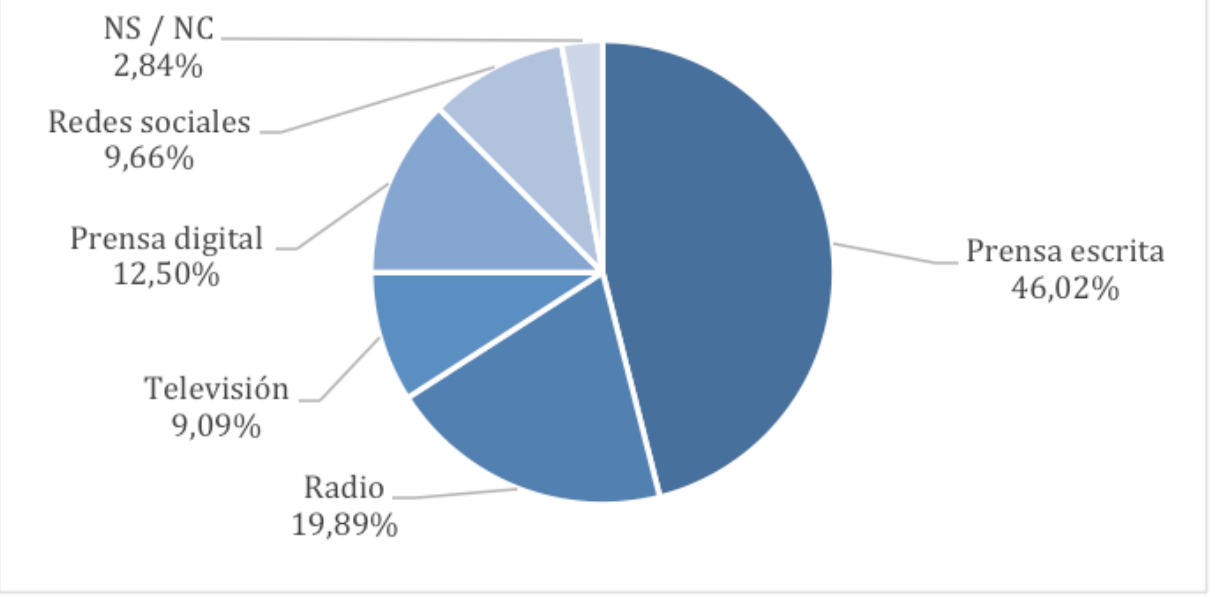

Fuente: elaboración propia.

Por otra parte, es llamativa la escasa confianza que capacidad de generar credibilidad informativa (menos les merece la televisión como medio informativo. Para del 10\%).

los jóvenes estudiantes de periodismo, tiene baja 
Esta aparente contradicción entre uso del medio para propósitos informativos y credibilidad de las noticias tiene su explicación en un complejo fenómeno presente en la sociedad de hoy. Los usuarios valoran los medios digitales porque les mantienen en contacto con la realidad con una amplia gama de noticias. Es una tendencia al empleo de los medios sociales como herramienta informativa, sin embargo son perfectamente conscientes de las deficiencias informativas que este canal puede ofrecer y otorgan a la prensa escrita ese sorprendente rango de credibilidad (46\%).

En el análisis desagregado por año (gráfico 13), estos datos sufren escasa variación, aunque es destacable el hecho de que la televisión pierde credibilidad como medio informativo en cursos avanzados, al mismo tiempo que la radio la gana. Prensa digital y redes sociales son medios que generan escasa confianza en todos los cursos, inferiores siempre al $20 \%$ de credibilidad.

Gráfico 13: Credibilidad de los medios desagregado por curso.

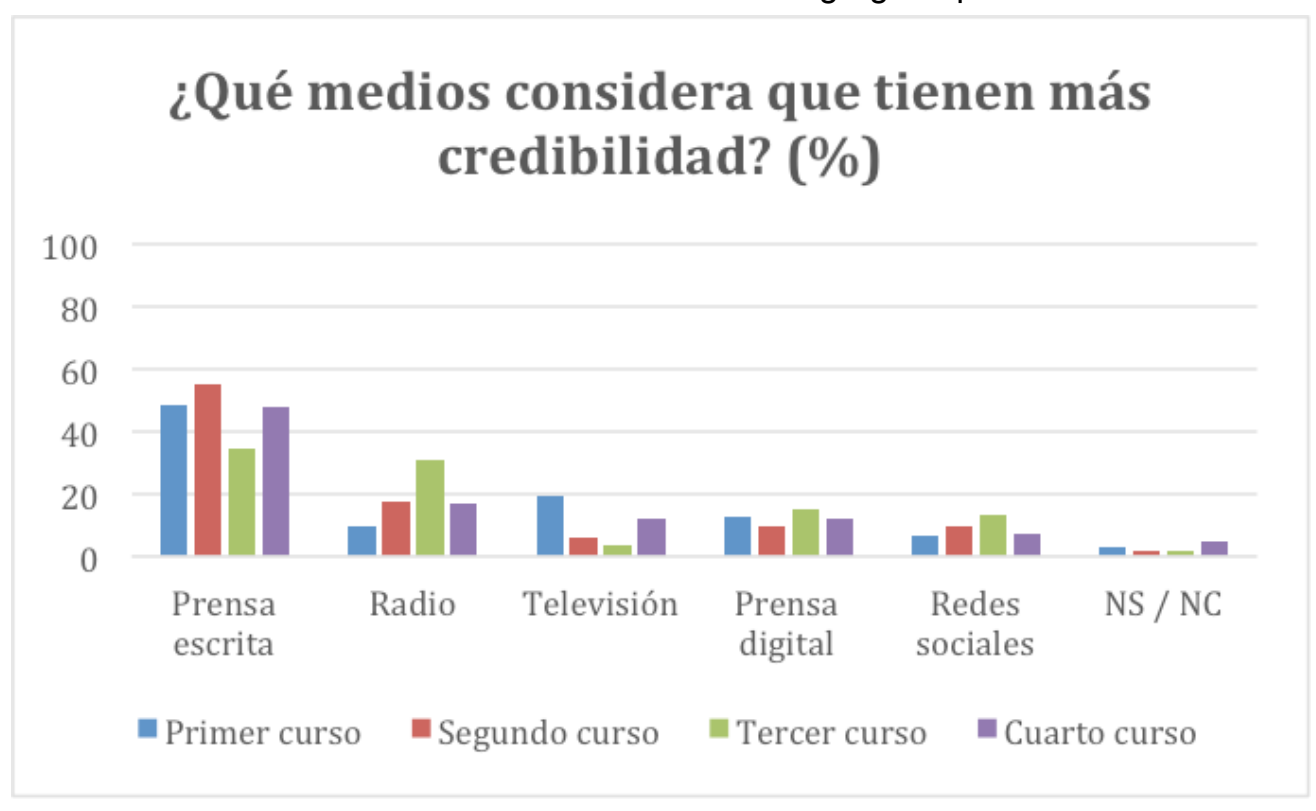

Fuente: elaboración propia.

Gangadharbatla et al. (2014) ponen de manifiesto que los jóvenes ya no plantean una sola forma de acceso a las noticias. Una posible explicación se deriva de que los jóvenes pueden tener el primer contacto con un hecho en los medios sociales o internet, pero después acuden al medio tradicional para tareas de confirmación y verificación. Otra explicación está relacionada con la tecnología "self-efficacy". Así, los individuos optan por una herramienta que puede ser útil en determinados usos y casos, dando priridad a esta variante ante otros criterios (Catalina-García et al., 2015). 
Gráfico 14: Grupos de afinidad informativa a nivel agregado.

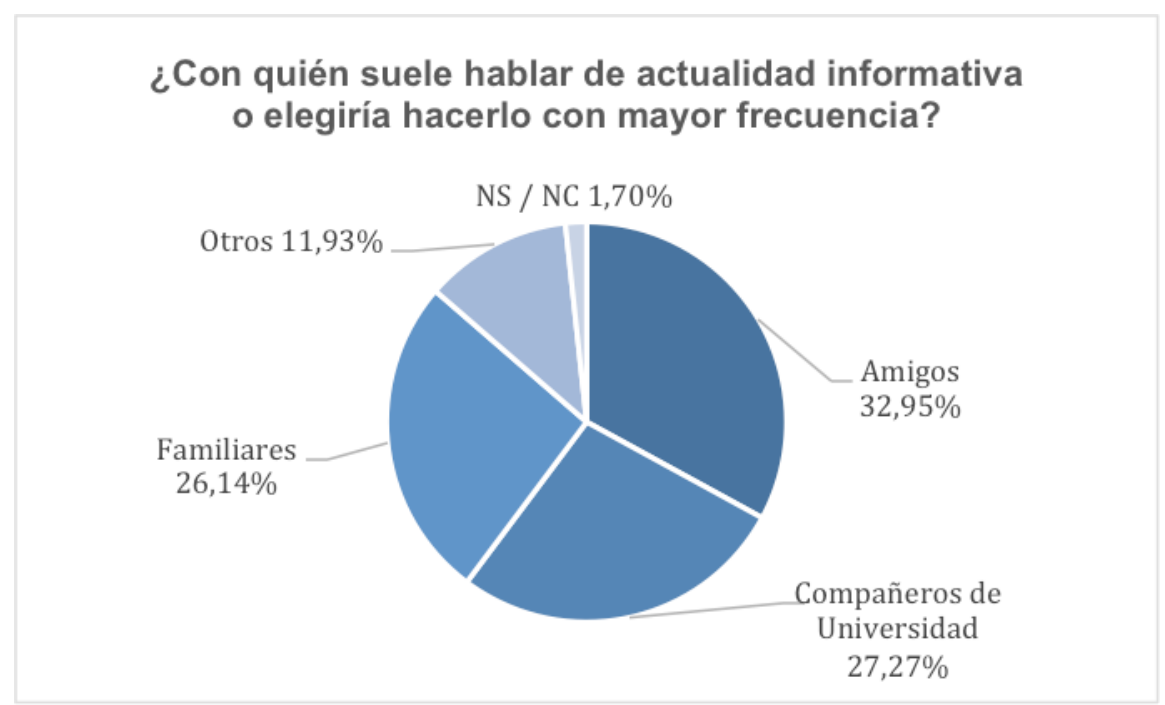

Fuente: elaboración propia.

La actualidad informativa es un tema de conversación familiares (26\%). Poniendo así de relieve, que es un que los estudiantes comparten (gráfico 14) a partes tema de importancia en todas las esferas de su vida bastante uniformes tanto con amigos (33\%) como social. con compañeros de universidad $(27 \%)$ como con

Gráfico 15: Grupos de afinidad informativa desagregado por curso.

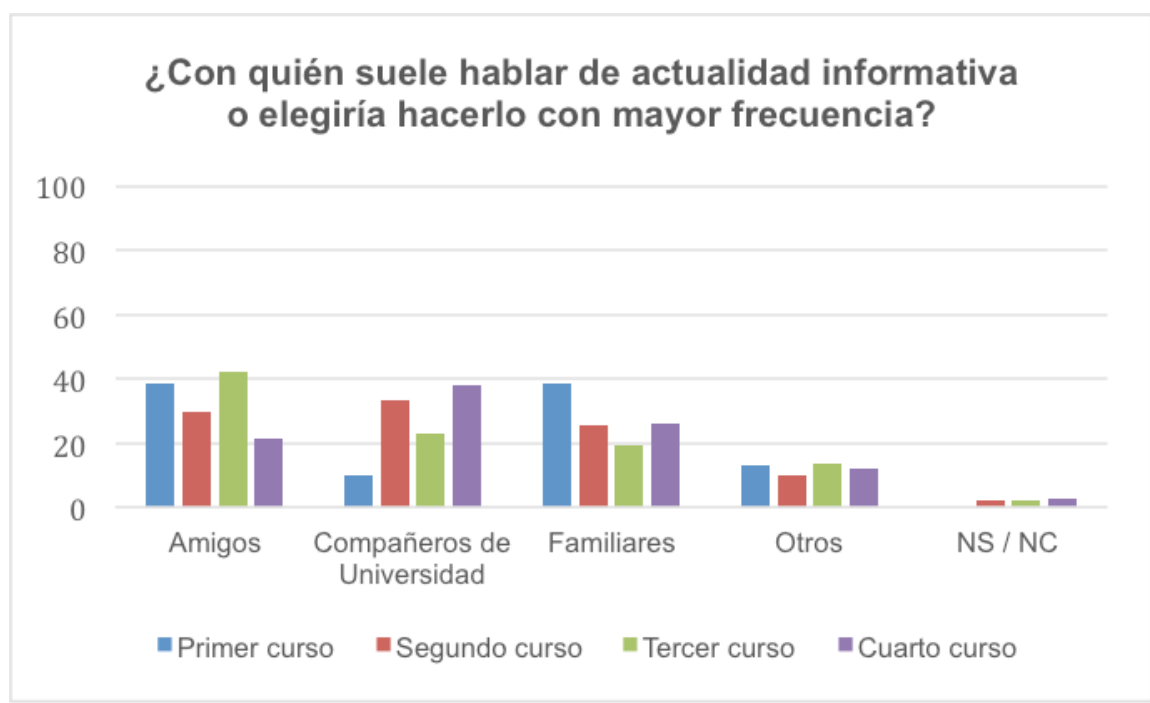

Fuente: elaboración propia.

Se observa que en cursos superiores el interés por curso), mientras que decae este comportamiento con compartir información con compañeros de universidad familiares (26\%) y amigos (21\%). Un mayor atractivo aumenta (hasta un $38 \%$ en estudiantes de cuarto por la materia prima de su cada vez más próxima 
profesión, hace que compartir conversaciones con compañeros sobre noticias esté más presente en el grupo entrevistado.

Gráfico 16: Grado de interés por tema informativo a nivel agregado

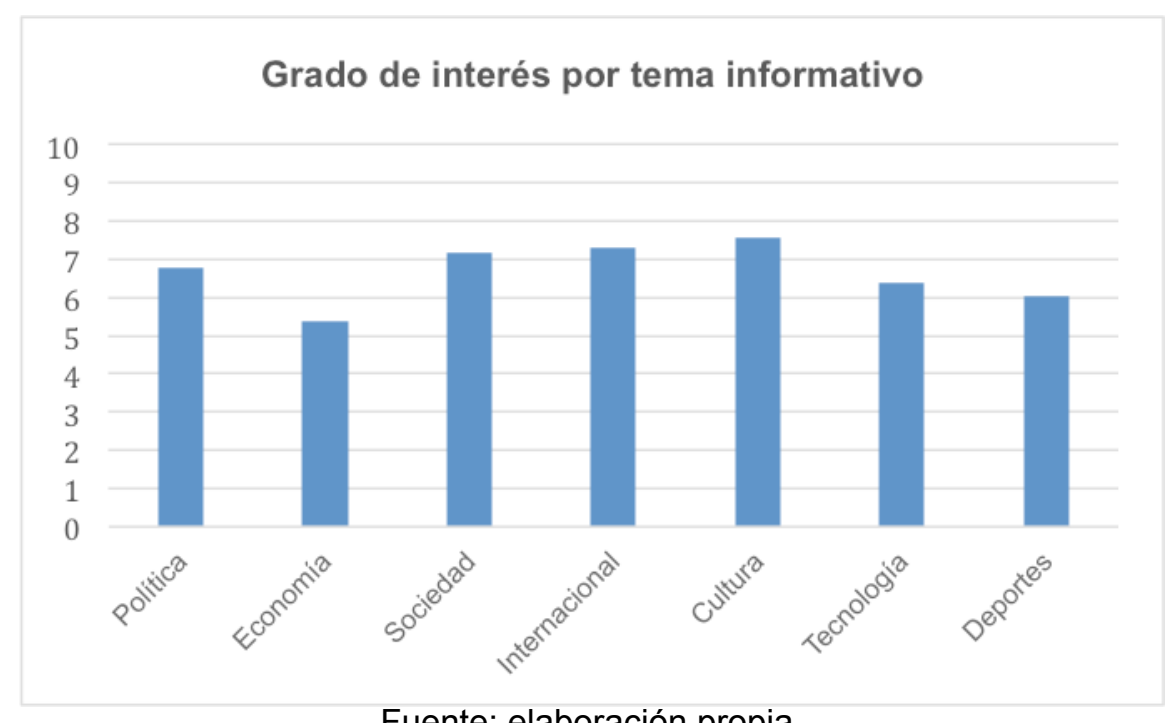

Fuente: elaboración propia.

La atención en materia informativa se centra en la las noticias de materia política, pasando de un 6,60 temática cultural $(7,55)$, internacional $(7,31)$ y social a un 7,10 mientras que su inclinación por los temas $(7,15)$. La economía ocupa el último lugar en grado de económicos decae de un 5,87 a un 5,26. Asimismo, interés con un 5,38 de valoración. se puede apreciar que su preferencia por las noticias A medida que se avanza en los estudios universitarios, de ámbito tecnológico es superior en el primer curso los jóvenes de periodismo incrementan su lectura en $\quad(7,71)$ que en el último $(7,57)$.

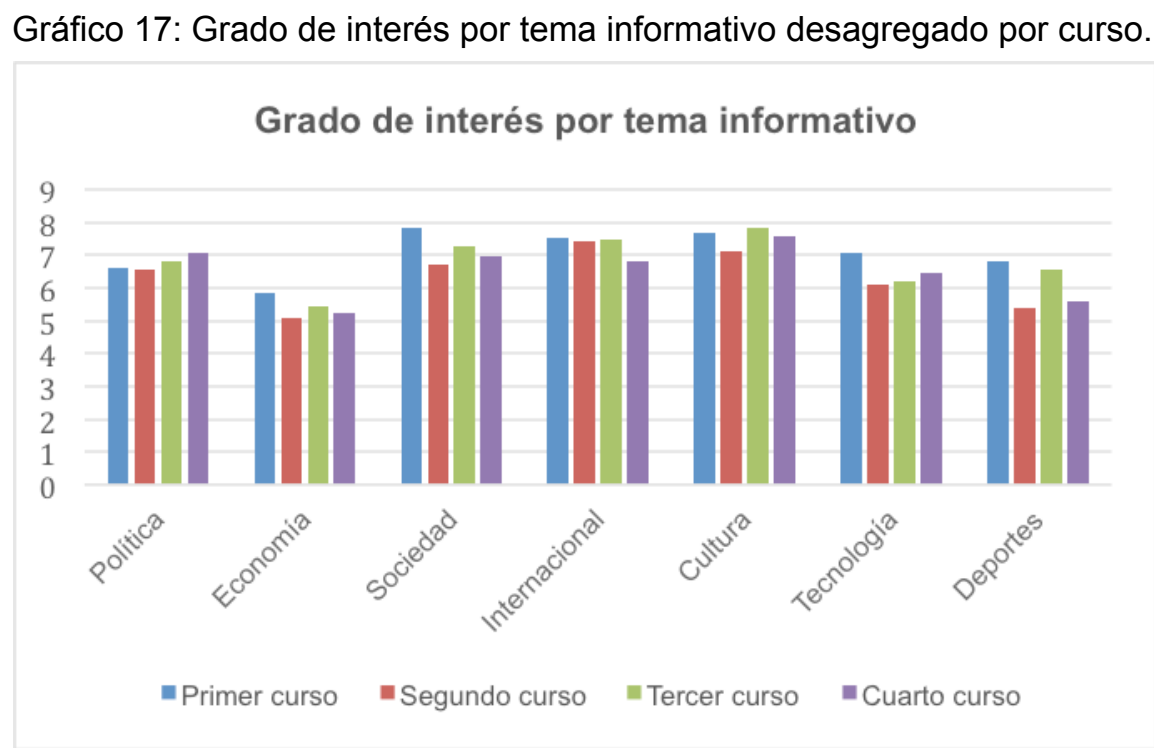

Fuente: elaboración propia. 


\section{CONCLUSIONES}

El análisis de hábitos de consumo de informaciones de estudiantes de periodismo goza de un doble interés, ya que, por una parte son consumidores de noticia a nivel personal; y por otra parte serán los profesionales de mañana que trabajarán con una materia prima (la noticia) que está cambiando continuamente de canal y de soporte; por lo que la importancia de este tipo de investigaciones aporta resultados significativos de los que se podrán concluir tendencias de evolución de la propia actividad periodística en el futuro cercano.

Una actividad periodística que debe ir enfocada y orientada a una demanda que, definitivamente será canalizada a través de medios y dispositivos digitales. Una demanda que exigirá cada vez mayor inmediatez y capacidad de actualización, como revela el hecho de que el acceso a las noticias es fundamentalmente a través de teléfonos inteligentes y se accede a ellas a través de las redes sociales. Es destacable el hecho de que más del $80 \%$ de los encuestados acceden a las informaciones al menos una vez al día y a través de smartphones, esta circunstancia coincide con la señalada por Mitchell et al. (2016) en un estudio realizado para consumidores de noticias norteamericanos.

La velocidad de acceso a las noticias y el principal medio utilizado (redes sociales) entran en contradicción con la veracidad y la credibilidad de la información, pero ésta pasa a un segundo plano como revela el hecho de que el medio considerado más veraz por los estudiantes, la prensa escrita, es el menos preferido para el consumo de noticias. Una de cal y otra de arena. Los periódicos impresos deben resaltar sus fortalezas como medios de mayor credibilidad y buscar fórmulas que acerquen las noticias de mayor interés local a sus lectores. Aún así, prensa digital y redes sociales son fuentes de más veracidad informativa que la televisión que se encuentra en el último lugar en términos de credibilidad informativa.

Las redes sociales reproducen el número de informadores y amplifican las noticias. Cada miembro de la red es un "informante" dispuesto a compartir noticias de interés con sus grupos de afinidad, multiplicándose así la cantidad de medios utilizados y realizando una labor de filtro en función de los intereses del grupo.

En los estudiantes de periodismo el interés por la actualidad informativa está más presente en los temas culturales, internacionales y de sociedad, frente a contenidos a priori más complejos como política o economía.

Los consumidores de noticias ya hoy obtienen de una forma gratuita toda la información que necesitan, no obstante, le conceden valor a la información y por ello estarían dispuestos a pagar un precio por obtenerla (más de un $30 \%$ ) a través de canales digitales.

Así, inmediatez, comodidad, accesibilidad y movilidad son las carácterísticas dominantes que deben contener los proveedores de noticias de mañana para satisfacer a un público ávido de novedades y los medios de comunicación deberán hacer un esfuerzo para orientarse a unos demandantes de noticias cada vez más exigiente e interesado en noticias específicas y no de ámbito generalista.

La gratuidad es un elemento circunstancial ya que los medios podrán establecer un precio a sus informaciones siempre y cuando sean inmediatas, estén actualizadas y accesibles para los consumidores, siempre y cuando la información que se ofrezca pueda ser "customizable" a nivel de consumidor, es decir, que 
se le ofrezca a cada persona única y estrictamente lo que desea, o, en otras palabras, que no se le venda lo que no desea y por lo que no están dispuestos a pagar.

Finalmente, no se debe olvidar que los hábitos de acceso a las noticias de los jóvenes de hoy representarán las pautas de consumo de la sociedad de mañana, por ello, habrá que estar muy atentos a la evolución de las mismas en orden de que la oferta de noticas de los medios se ajuste a la demanda de información de la sociedad. Por ello, los medios de comunicación deben hacer un esfuerzo de adaptación a las nuevas tecnologías oriéntandose a un cliente hiperconectado y con necesidades de inflación informativa cada vez más patentes.

En una doble vertiente, esta encuesta está dirigida también a futuros profesionales del mundo periodístico, que ofrecerán contenidos informativos a la sociedad. Este hecho constituye un reto para la Universidad de hoy, que debe hacer un doble esfuerzo por configurar dentro de las aulas todo lo que sea necesario para ofrecer a la sociedad, profesionales que enriquezcan un escenario periodístico en el que la contrastación, la veracidad, la rigurosidad y la credibilidad no estén influidas por el canal de comunicación, ni alteradas por la inmediatez. Los futuros periodistas deben incorporar, intrínsecamente dichos valores en los nuevos canales informativos. Valores que son reconocidos por los estudiantes como demuestra el hecho de la confiabilidad que le merece la prensa escrita frente a los medios digitales.

El futuro que se avecina para la "prensa tradicional" es un cambio de modelo de negocio, las noticias por canales digitales deberán empezar a monetizarse, los contenidos deberán ser más adaptados y personalizados a los intereses de cada consumidor, ese es el verdadero valor añadido que la sociedad demandará y que no puede ser obviado.

Este es un trabajo preliminar, que será ampliado en un futuro extendiendo el alcance metodológico a otros ámbitos universitarios para poder extraer conclusiones más robustas y generalizables que contribuyan a conocer más la realidad de nuestro sector e impulsar el buen periodismo dentro de nuestra sociedad.

\section{REFERENCIAS}

$20^{\circ}$ Encuesta AIMC a usuarios de internet. Madrid:Asociación para la investigación de medios de comunicación. (AMIC). 2018

Casero-Ripollés, A. (2012); Más allá de los diarios: el consumo de noticias de los jóvenes en la era digital. Comunicar, $n^{\circ}$ 39, V. XX. pp 151-158.

Casero-Ripollés, A.; Ortells-Badenes, S.; Doménech-Fabregat, H. (2013). “Las competencias profesionales en periodismo: una evaluación comparativa”. Historia y Comunicación Social, v. 18, pp. 53-64.

Catalina-García, B; García, A.; Montes, M. (2015): Jóvenes y consumo de noticias a través de internet y los medios sociales. Historia y Comunicación Social. Vol 20. Num 2. pp 601-619.

Condeza, R.; Bachmann, I.; Mujica, C. (2014). El consumo de noticias de los adolescentes chilenos: intereses, motivaciones y percepciones sobre la agenda informativa. Comunicar, 43(XXII), pp. 55-64. http://dx.doi.org/10.3916/C43-2014$\underline{05}$ (Consultado el 15 de febrero de 2018).

Gangadharbatla, H.; Bright, L. F.; Logan, K. (2014). Social Media and news gathering: tapping into the millennial mindset. 
The Journal of Social Media in Society, 3(1), pp. 45-63.

Humanes, M-L.; Roses, S. (2014). "Valoración de los estudiantes sobre la enseñanza del Periodismo en España”. Comunicar, v. XXI, n. 42, pp.181-188. Accesible en: www.revistacomunicar.com/verpdf.php?numero=42\&articulo=42 (Consultado el 20 de febrero de 2018)

Kim, K.-S., Sin, S.-C. J.; He, Y. (2013). Information seeking through social media: impact of user characteristics on social media use. Proceedings of the American Society for Information Science and Technology, 50(1), pp. 1-4.

Livingstone, S., Haddon, L., Görzig, A. and Olafson, K. (2011). Risks and safety on the Internet. The perspective of European children. Final report.London: London School of Economics and Political Science. Accesible en http:// www.eukidsonline.net (Consultado el 13 de febrero 2018).

Mc Luhan, M. y Pavers, BR (1989). La aldea global. Editorial Gedisea. Barcelona. España.

Martín Algarra, M.(2005) "Las tecnologías periodísticas desde ayer al mañana" sociedad española de periodística. - Cáp. 1 "Periodismo, tecnología y modernidad. Accesible en http://www.periodistica.es/sep2016r/images/Ep_Sevilla.pdf (Consultado el 15 de 01 de 2018)

Mitchell, A.; Gottfried, J.; Barthel, M. y Shearer, E. (2016). The Modern News Consumer. Pew Research Center. Accesible en: www.journalism.org/.../PJ 2016.07.07 Modern-News-Consumer... http://www.journalism.org/files/2016/07/ PJ 2016.07.07 Modern-News-Consumer FINAL.pdf (Consultado el 05 de 02 de 2018)

Prensky, M. (2008). Digital natives,digital inmigrants. On the Horizon. MCB University Press, Vol. 9 No. 5.Accesible en http://marcprensky.com/writing/Prensky\%20-\%20Digital\%20Natives,\%20Digital\%20Immigrants\%20-\%20Part1. pdf (Consultado el 22 de febrero de 2018)

Varela, J. (2005) "Periodismo 3.0 La socialización de la información". España. Accesible en. www.periodistas21.blogspot. com. Blogs vs. MSM. Periodismo 3.0, la socialización de la información. (Consultado el 20 de enero de 2018).

Yuste, Bárbara (2015): Las nuevas formas de consumir información de los jóvenes. Revista de Estudios de Juventud. $\mathrm{N}^{\circ}$ 108. pp 179-191. Accesible en http://www.injuve.es/observatorio/infotecnologia/108-jovenes-y-generacion-2020 (Consultado el 16 de febrero de 2018)

\section{ANEXO I}

\section{Encuesta sobre los hábitos de consumo de noticias para estudiantes de la Universidad de Sevilla}

1. ¿En qué curso se encuentra actualmente?

\begin{tabular}{|c|c|c|}
\hline & Respuestas & Porcentaje \\
\hline Primer curso & 31 & 17,61 \\
\hline Segundo curso & 51 & 28,98 \\
\hline Tercer curso & 52 & 29,55 \\
\hline Cuarto curso & 42 & 23,86 \\
\hline Total & 176 & 100,00 \\
\hline
\end{tabular}


2. ¿Qué medio de comunicación/plataforma suele elegir a la hora de informarse? (Ordene por orden de preferencia del 1 al 5 , siendo 1 la de mayor preferencia y 5 la de menos).

\begin{tabular}{|c|c|c|c|c|c|c|}
\hline & $\frac{\text { Prensa }}{\underline{\text { escrita }}}$ & $\underline{\text { Radio }}$ & Televisión & $\frac{\frac{\text { Prens a }}{\text { digital } 1}}{\text { internet }}$ & $\frac{\text { Red es }}{\underline{\text { sociales }}}$ & $\underline{\mathrm{NS} / \mathrm{NC}}$ \\
\hline Primer curso & 3,26 & 3,19 & 2,55 & 1,94 & 2,58 & 1,48 \\
\hline Segundo curso & 3,86 & 3,45 & 2,53 & 1,90 & 2,65 & 0,61 \\
\hline Tercer curso & 3,54 & 3,00 & 3,23 & 2,23 & 2,79 & 0,21 \\
\hline Cuarto curso & 3,95 & 2,98 & 3,05 & 2,14 & 2,33 & 0,55 \\
\hline Total & 3,65 & 3,16 & 2,84 & 2,05 & 2,59 & 0,71 \\
\hline
\end{tabular}

3. Cuando utiliza un smartphone o tablet, ¿cómo suele acceder a la páginas de noticias?

\begin{tabular}{|c|c|c|c|c|c|}
\hline & $\begin{array}{l}\text { APP de } \\
\text { cada me- } \\
\underline{\text { dio }}\end{array}$ & $\frac{\mathrm{Redes}}{\underline{\text { sociales }}}$ & Navegador & $\begin{array}{l}\text { Agregador de } \\
\underline{\text { noticias }}\end{array}$ & $\underline{N S / N C}$ \\
\hline Primer curso & 6 & 9 & 14 & 2 & 0 \\
\hline Segundo curso & 13 & 11 & 17 & 4 & 2 \\
\hline Tercer curso & 9 & 21 & 20 & 1 & 0 \\
\hline Cuarto curso & 10 & 17 & 10 & 4 & 1 \\
\hline Total & 38 & 58 & 61 & 11 & 3 \\
\hline
\end{tabular}

4. ¿A la hora de consumir prensa digital, ¿qué dispositivo utiliza con mayor frecuencia?

\begin{tabular}{|c|c|c|c|c|}
\hline & Smartphone & $\begin{array}{l}\text { Ordenador personal o } \\
\text { portátil }\end{array}$ & $\underline{\text { Tablet }}$ & $\underline{\mathrm{NS} / \mathrm{NC}}$ \\
\hline Primer curso & 21 & 7 & 3 & 0 \\
\hline Segundo curso & 37 & 10 & 2 & 2 \\
\hline Tercer curso & 36 & 15 & 1 & 0 \\
\hline Cuarto curso & 32 & 8 & 1 & 1 \\
\hline Total & 126 & 40 & 7 & 3 \\
\hline
\end{tabular}

5. ¿Con qué frecuencia suele consumir información?

\begin{tabular}{|c|c|c|c|c|c|}
\hline & $\frac{1 \text { vez a la }}{\underline{\text { semana }}}$ & $\frac{2-3 \quad \text { veces }}{\text { por semana }}$ & $\underline{\text { A diario }}$ & $\underline{\text { Sin regularidad }}$ & $\underline{\mathrm{NS} / \mathrm{NC}}$ \\
\hline Primer curso & 0 & 2 & 27 & 1 & 1 \\
\hline Segundo curso & 1 & 7 & 37 & 5 & 1 \\
\hline Tercer curso & 1 & 4 & 46 & 1 & 0 \\
\hline Cuarto curso & 0 & 2 & 38 & 1 & 1 \\
\hline Total & 2 & 15 & 148 & 8 & 3 \\
\hline
\end{tabular}


6. ¿Es socio o suscriptor de algún diario digital?

\begin{tabular}{|c|c|c|c|c|c|}
\hline & $\frac{\text { No, lo quiero }}{\text { gratis }}$ & $\begin{array}{l}\text { No, pagaría } \\
\underline{\text { hasta } 6 \text { euros }}\end{array}$ & $\underline{\text { Si }}$ & $\begin{array}{l}\text { No, pagaría más } \\
\underline{\text { de } 6 \text { euros }}\end{array}$ & $\underline{\mathrm{NS} / \mathrm{NC}}$ \\
\hline Primer curso & 24 & 2 & 4 & 1 & 0 \\
\hline Segundo curso & 26 & 16 & 3 & 4 & 2 \\
\hline Tercer curso & 31 & 15 & 5 & 1 & 0 \\
\hline Cuarto curso & 25 & 12 & 0 & 4 & 1 \\
\hline
\end{tabular}

7. ¿Qué medios considera que tienen más credibilidad? (Ordene del 1 al 5 , siendo 1 el de mayor credibilidad y 5 el de menos).

\begin{tabular}{|c|c|c|c|c|c|c|}
\hline & $\begin{array}{l}\text { Prensa } \\
\text { escrita }\end{array}$ & $\underline{\text { Radio }}$ & $\underline{\text { Televisión }}$ & $\frac{\text { Prens a }}{\text { digital }}$ & $\frac{\mathrm{Redes}}{\underline{\text { sociales }}}$ & $\underline{N S / N C}$ \\
\hline Primer curso & 1,94 & 2,68 & 2,81 & 3,00 & 4,10 & 0,48 \\
\hline Segundo curso & 1,82 & 2,75 & 3,41 & 2,51 & 4,22 & 0,29 \\
\hline Tercer curso & 2,19 & 2,23 & 3,38 & 2,92 & 4,08 & 0,19 \\
\hline Cuarto curso & 1,86 & 2,31 & 3,21 & 2,52 & 4,07 & 1,02 \\
\hline Total & 1,95 & 2,49 & 3,20 & 2,74 & 4,12 & 0,50 \\
\hline
\end{tabular}

8. Indique el grado de interés (1-10) en la siguiente sección o tema informativo (siendo 1 el interés mínimo y 10 el interés máximo).

\begin{tabular}{|c|c|c|c|c|}
\hline & Política & Economía & Sociedad & Internacional \\
\hline Primer curso & 6,61 & 5,87 & 7,84 & 7,52 \\
\hline Segundo curso & 6,57 & 5,10 & 6,75 & 7,41 \\
\hline Tercer curso & 6,83 & 5,44 & 7,27 & 7,48 \\
\hline Cuarto curso & 7,07 & 5,26 & 6,98 & 6,81 \\
\hline Total & 6,77 & 5,38 & 7,15 & 7,31 \\
\hline
\end{tabular}

\begin{tabular}{|c|c|c|c|}
\hline & Cultura & Tecnología & Deportes \\
\hline Primer curso & 7,71 & 7,10 & 6,81 \\
\hline Segundo curso & 7,12 & 6,12 & 5,37 \\
\hline Tercer curso & 7,85 & 6,19 & 6,56 \\
\hline Cuarto curso & 7,57 & 6,45 & 5,60 \\
\hline Total & 7,55 & 6,39 & 6,03 \\
\hline
\end{tabular}


9. ¿Con quién suele hablar de actualidad informativa o elegiría hacerlo con mayor frecuencia? (Ordene por preferencia del 1 al 4 , siendo 1 el de mayor preferencia y 4 el de menos).

\begin{tabular}{|c|c|c|c|c|c|}
\hline & $\underline{\text { Amigos }}$ & $\begin{array}{l}\text { Compañeros de } \\
\underline{\text { Universidad }}\end{array}$ & Familiares & $\underline{\text { Otros }}$ & $\underline{\mathrm{NS} / \mathrm{NC}}$ \\
\hline Primer curso & 2,00 & 2,45 & 2,03 & 3,10 & 0,42 \\
\hline Segundo curso & 2,14 & 1,90 & 2,25 & 3,43 & 0,27 \\
\hline Tercer curso & 1,96 & 2,31 & 2,31 & 3,40 & 0,02 \\
\hline Cuarto curso & 2,12 & 2,00 & 2,31 & 3,24 & 0,33 \\
\hline Total & 2,05 & 2,17 & 2,23 & 3,29 & 0,26 \\
\hline
\end{tabular}

